\title{
Thermospheric vertical winds in the auroral oval/polar cap region
}

\author{
P. A. Greet ${ }^{1}$, J. L. Innis ${ }^{1,2}$, and P. L. Dyson ${ }^{3}$ \\ ${ }^{1}$ Australian Antarctic Division, Kingston, Tasmania, 7050, Australia \\ ${ }^{2}$ Geophysical Institute, University of Alaska, Fairbanks, USA \\ ${ }^{3}$ Department of Physics, La Trobe University, Victoria, 3086, Australia \\ Received: 27 August 2001 - Revised: 20 December 2001 - Accepted: 23 May 2002
}

\begin{abstract}
Thermospheric mean vertical winds from highresolution Fabry-Perot Spectrometer observations of the $\lambda 630 \mathrm{~nm}$ emission (from $\sim 240 \mathrm{~km}$ altitude), over a four year interval $1997-2000$, from Mawson $\left(67.6^{\circ} \mathrm{S}, 62.9^{\circ} \mathrm{E}\right.$, Inv $\left.70.5^{\circ} \mathrm{S}\right)$ and Davis $\left(68.6^{\circ} \mathrm{S}, 78.0^{\circ} \mathrm{E}\right.$, Inv $\left.74.6^{\circ} \mathrm{S}\right)$ are presented. Combining the four years of data shows Mawson mean hourly vertical winds vary between $-10 \mathrm{~m} \mathrm{~s}^{-1}$ and $+4 \mathrm{~m} \mathrm{~s}^{-1}$, while Davis mean hourly vertical winds vary between $-10 \mathrm{~m} \mathrm{~s}^{-1}$ and $+10 \mathrm{~m} \mathrm{~s}^{-1}$. Mean hourly vertical winds from Mawson show little change with $K_{p}$, while at Davis the range of variation increases with increasing geomagnetic activity. Histograms of frequency distributions of such winds, and their variations with $K_{p}$ and $\lambda 630 \mathrm{~nm}$ emission intensity, are presented and discussed. Variations in mean hourly thermospheric winds and $\lambda 630 \mathrm{~nm}$ emission intensities show at least three significant associations between mean vertical winds and the auroral oval. Mean vertical winds within the auroral oval are smaller than those outside the oval, particularly those in the polar cap. A downward wind associated with entry of the observing region into the auroral oval can be seen in both Mawson and Davis hourly mean vertical winds. Large vertical winds are seen poleward of the auroral oval/polar cap boundary, most significantly upward winds occur within $\pm 2 \mathrm{hr}$ of magnetic midnight. Under moderately quiet geomagnetic conditions Davis passes through the auroral oval into the polar cap in the evening, but at higher $K_{p}$ it passes into the polar cap earlier and larger, and more sustained mean vertical winds are observed.
\end{abstract}

Key words. Meteorology and atmospheric dynamics (thermospheric dynamics)

\section{Introduction}

Vertical winds in the thermosphere have a number of possible sources. Smith (1998) identified a diurnal expansion and contraction of the thermosphere, localized heating (for ex-

Correspondence to: P. A. Greet

(pene.greet@paradise.net.nz) ample, auroral heating), and wave motions. The diurnal cycle is in response to the daily solar heating and is expected to be $\sim 1-3 \mathrm{~m} \mathrm{~s}^{-1}$ (Smith, 1998). Large vertical winds, $\sim 100$ $200 \mathrm{~m} \mathrm{~s}^{-1}$, have been observed at auroral latitudes with both satellite (e.g. Spencer et al., 1982) and ground-based instruments (e.g. Price et al., 1995; Innis et al., 1999). Thermospheric waves also manifest in vertical winds with amplitudes of up to $100 \mathrm{~m} \mathrm{~s}^{-1}$ (Johnson et al., 1995). Waves are seen propagating both equatorward and poleward of the auroral oval, and relevant observations have been reviewed by Innis et al. (2001).

Fabry-Perot Spectrometers, FPSs, with high-spectral resolution, are routinely used for observations of the oxygen $\lambda 630 \mathrm{~nm}$ thermospheric emission, permitting measurements of emission intensity and thermospheric wind and temperature. The height of the emission varies depending on auroral activity, however, due to the long lifetime of the excited state and quenching by $\mathrm{N}_{2}$ below $200 \mathrm{~km}$ altitude, the emission is considered to originate from a peak height near $220-240 \mathrm{~km}$ altitude (e.g. Oyama et al., 2000) with a characteristic vertical width of about $50 \mathrm{~km}$. The mean vertical velocity over a night's observing is used to determine a zero velocity (e.g. Innis et al., 2001). Lack of an absolute zero-velocity reference is an inherent difficulty in making observations of vertical winds, as discussed by Aruliah and Rees (1995). Non-zero vertical winds can also significantly affect horizontal wind measurements (Innis et al., 1999). However, standard FPS analysis techniques are considered robust, for both horizontal and vertical winds, when used carefully.

Despite significant numbers of observations of thermospheric vertical winds, thermospheric models do not describe well the observations (e.g. Conde and Dyson, 1995; Smith, 1998). Difficulties include a lack of knowledge of mean thermospheric winds, and the resolution required by models to represent vertical wind horizontal structure, such as that associated with the auroral oval. A large vertical wind event seen simultaneously at Mawson and Davis (Innis et al., 1999) has been modelled by Sojka et al. (2001). During this vertical wind event a region of upward wind of areal extent $6 \times$ $10^{11} \mathrm{~m}^{2}$, or $\sim 1200 \mathrm{~km}$ east-west by $500 \mathrm{~km}$ north-south, was 
observed over several hours. Parcel trajectories are described and the model has shown that measurements of large vertical velocities over confined regions, at auroral latitudes, are reasonable. However, effects of such events on the long-term mean thermospheric dynamics are not yet well understood or modelled.

Ground-based FPSs can provide data sets from the one site extending over years and are hence ideal for establishing influences and variations in mean conditions. Studies of mean vertical winds determined from the oxygen $\lambda 630 \mathrm{~nm}$ thermospheric emission have been published (e.g. Conde and Dyson, 1995; Aruliah and Rees, 1995; Smith, 1998, for review of these and earlier works). Conde and Dyson (1995) studied one year of data from Mawson $\left(68^{\circ} \mathrm{S}, 63^{\circ} \mathrm{E}\right)$. Using 2096 zenith spectra, from 103 nights between 18 March and 20 September 1992, a dependence on magnetic activity was found. Data were divided into two groups, $K_{p}<3$ and $>3$. A diurnal variation on quiet days ranged from -2.6 to $+3.0 \mathrm{~m} \mathrm{~s}^{-1}$, while for the more active days the range was -6.8 to $+4.1 \mathrm{~m} \mathrm{~s}^{-1}$. Aruliah and Rees (1995) studied 1242 nights of data from a ten-year interval, 1981 to 1990 , using an instrument at Kiruna $\left(68^{\circ} \mathrm{N}, 20^{\circ} \mathrm{E}\right)$. They found dependencies on UT, season, geomagnetic activity and solar cycle, also noting that the location of the auroral oval is dependent on these parameters as well.

Mean vertical winds from observations of the oxygen $\lambda 630 \mathrm{~nm}$ thermospheric emission from two stations approximately $600 \mathrm{~km}$ apart are compared in this study. The FPS, as used by Conde and Dyson (1995), is located at Mawson $\left(67.6^{\circ} \mathrm{S}, 62.9^{\circ} \mathrm{E}, \mathrm{Inv} 70.5^{\circ} \mathrm{S}\right)$ and another similar instrument is located at Davis $\left(68.6^{\circ} \mathrm{S}, 78.0^{\circ} \mathrm{E}\right.$, Inv $\left.74.6^{\circ} \mathrm{S}\right)$. Both were operational for the four years 1997-2000. The Mawson instrument was decommissioned at the end of 2000. Simultaneous data from the two stations have been used to study thermospheric horizontal winds (Greet et al., 1999) and a single vertical wind event (Innis et al., 1999). Comparison of mean vertical winds from two such closely spaced stations will enable information on spatial variations in the polar region to be assessed, as well as variations with UT, geomagnetic activity, and location of the auroral oval.

\section{Instruments and data}

The Mawson and Davis FPSs have been described elsewhere (Jacka et al., 1980; Jacka, 1985; Greet et al., 1999). The instruments are run routinely with observations of mesospheric and thermospheric emissions on a campaign basis. Instrument configuration and operation during 1997-1999 is as described by Greet et al. (1999) and Innis et al. (2001).

All zenith observations of the oxygen $\lambda 630 \mathrm{~nm}$ emission, both those from zenith-only campaigns and those from cardinal-point campaigns, were included in this study. During zenith-only campaigns, profiles were acquired at intervals of approximately $420 \mathrm{~s}$, except during some 1999 campaigns at Davis, when the scan range was halved and profiles were acquired in $210 \mathrm{~s}$. During cardinal-point campaigns,
Table 1. $\lambda 630 \mathrm{~nm}$ observations from Mawson and Davis

\begin{tabular}{|c|c|c|c|c|c|}
\hline Station & year & profiles & $\begin{array}{l}\text { start } \\
\text { DOY }\end{array}$ & $\begin{array}{r}\text { stop } \\
\text { DOY }\end{array}$ & days \\
\hline Mawson & 1997 & 1644 & 145 & 298 & 33 \\
\hline Mawson & 1998 & 908 & 53 & 296 & 53 \\
\hline Mawson & 1999 & 1703 & 44 & 298 & 69 \\
\hline Mawson & 2000 & 1891 & 57 & 291 & 62 \\
\hline Mawson & $97-00$ & 6146 & & & 217 \\
\hline Davis & 1997 & 1581 & 111 & 294 & 66 \\
\hline Davis & 1998 & 1067 & 80 & 300 & 102 \\
\hline Davis & 1999 & 6601 & 60 & 283 & 61 \\
\hline Davis & 2000 & 1397 & 64 & 294 & 51 \\
\hline Davis & $97-00$ & 10646 & & & 280 \\
\hline
\end{tabular}

zenith observations were of similar duration but only obtained once every 30 to $60 \mathrm{~min}$. Exact observing sequences varied depending on campaigns in operation and the different observing conditions at the two stations.

Only data from cloud-free intervals were selected for use in this analysis, as scattering by cloud from off-zenith aurora can affect the vertical wind observation (Price et al., 1995). Observers' logs, all-sky auroral imager videos, and intensity variations were used to identify cloudy intervals. Observing is possible at Mawson and Davis between day-of-year, DOY, 44 and DOY300. In mid-winter $\lambda 630 \mathrm{~nm}$ emission observations are possible for up to 18 hours at both stations. Timing of twilight varies dramatically during autumn and spring equinoxes. To avoid contamination by twilight processes, profiles were rejected by selection criteria based on background values. Profiles with low signal-power to noisepower ratios were also rejected. Table 1 shows the number of profiles, the first and last DOY of observations for each year, and the number of days in which data have been included in the analysis.

Solar activity increased during the interval from 1997 to 2000. During most of the 1997 observing season conditions were those of solar minimum, where F10.7 ranged from 70 to 100 , with the higher values towards the end of the observing season. During 2000 F10.7 ranged from 130 to 250. Conditions in 1998 and 1999 gradually increased towards higher activity. By averaging planetary $K_{p}$ values at the time of each profile, a mean and median $K_{p}$ can be found. Both the mean and median $K_{p}$ were significantly lower during 1997 than in other years and higher during 2000 than in other years.

\section{Results}

Hourly mean vertical winds and intensities from Davis for the four years are shown in Fig. 1. All accepted data have been given equal weight. We adopt the usual convention that upward winds are positive, and downward winds are nega- 

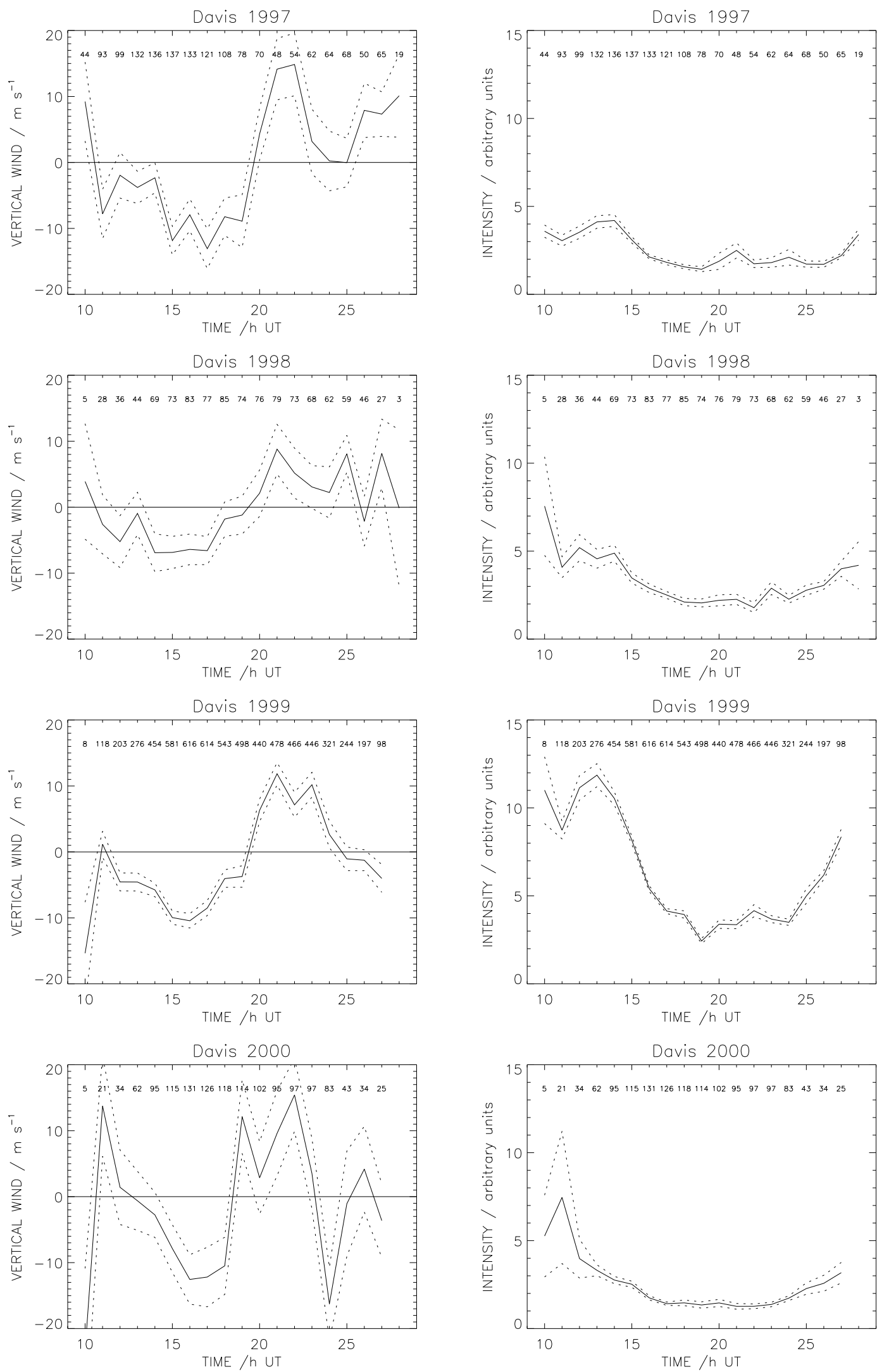

Fig. 1. Hourly averaged vertical wind and intensity for Davis, for the years 1997-2000. Standard errors in hourly means are indicated by dashed lines. The number of points in each hourly mean is written at the top of each plot. 

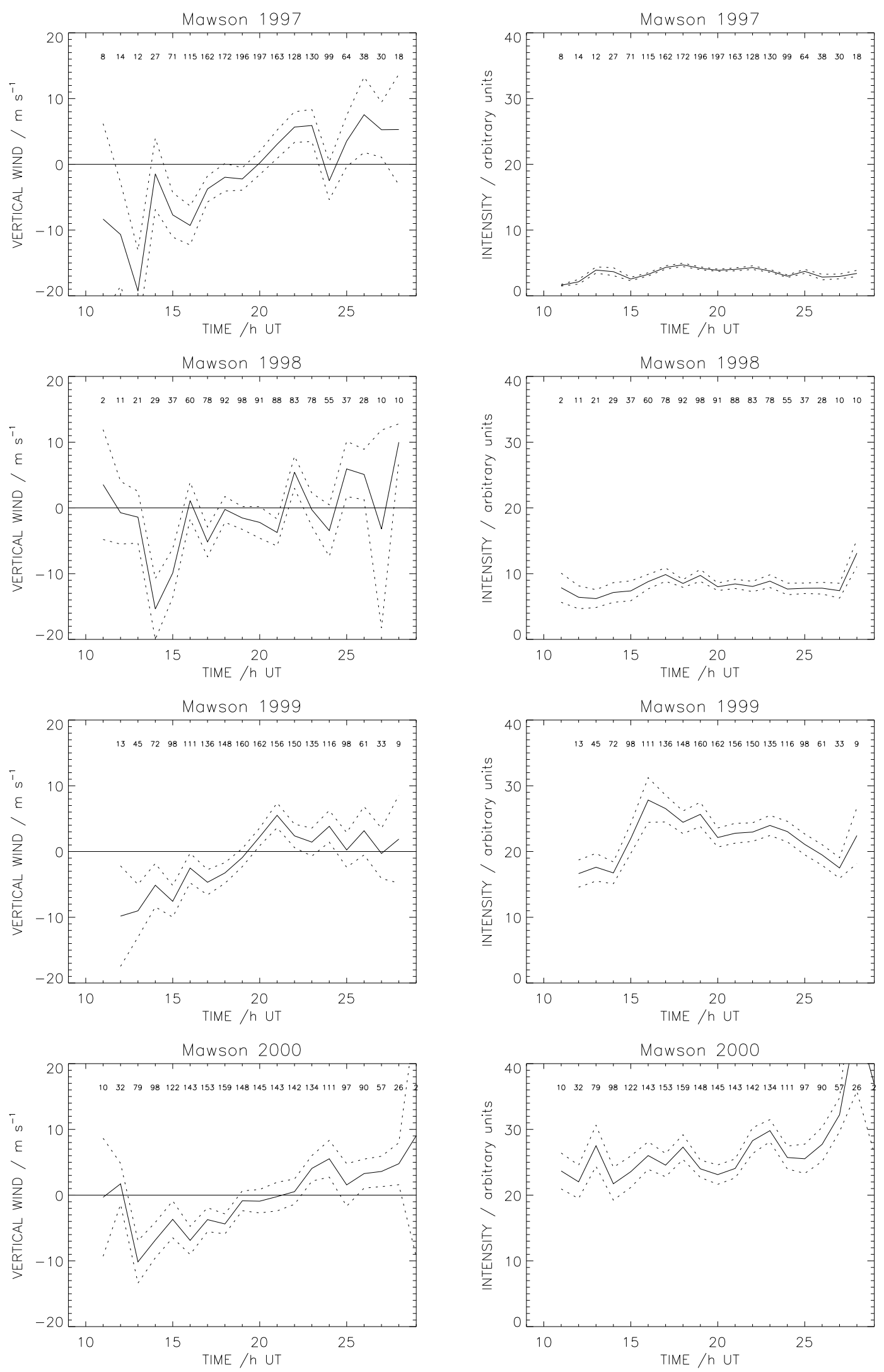

Fig. 2. Hourly averaged vertical wind and intensity for Mawson, for the years 1997-2000. Standard errors in hourly means are indicated by dashed lines. The number of points in each hourly mean is written at the top of each plot. 
tive. It should be noted that no absolute intensity calibrations have been performed. Values are given for relative intensity, and will be used mainly for qualitative assessments, but we note that the relative intensity measurement scales from Mawson and Davis are approximately equivalent and may be compared directly. The number of profiles included in each hourly average is indicated at the top of each plot. Variations from year to year and in the number of data points reflect the number of zenith-only campaigns, instrument down time, and observing conditions. Standard errors in hourly means are indicated by dashed lines.

FPS profiles can determine three parameters; emission intensity, thermospheric wind and temperature. Hourly mean temperatures are not shown, since they have little diurnal structure, although, as expected, they generally rise with increasing solar activity. In 1997 the mean temperature was around $\sim 800 \mathrm{~K}$ at both Davis and Mawson, although slightly higher at Davis. In 2000 the mean temperature was $\sim 1000 \mathrm{~K}$ at Mawson and $\sim 1300 \mathrm{~K}$ at Davis. Lower intensities during 2000 suggest that Davis was more frequently inside the polar cap in that year (Innis et al., 1996). Variations in mean intensities, together with auroral videos, provide good indications of auroral conditions. Davis is usually either north of, or under, the discrete auroral oval in the early evening. The Davis observing region passes through the oval and into the polar cap by $\sim 16: 00$ UT and generally stays within the polar cap for the remainder of the night, except when the auroral oval expands during substorms, particularly after magnetic midnight (21:52 UT at Davis, 22:32 UT at Mawson). In the polar cap the emission intensity is very low, however, the hourly mean emission intensity increases in the early morning due to either photochemical processes associated with dawn and/or reentry into the auroral oval.

Davis hourly average vertical winds show some features common to all years. The wind is generally negative from 11:00 to 19:00 UT and positive from 20:00 to 25:00 UT. The positive phase is more structured than the negative phase. Although averages are affected by the number of points obtained each year, amplitude of the hourly mean variation is of a similar order of magnitude, about $\pm 10 \mathrm{~m} \mathrm{~s}^{-1}$. The hourly mean variation does not appear to be a simple sinusoid.

Hourly mean vertical winds and intensities from Mawson for the four years are shown in Fig. 2. Although Mawson and Davis are separated by only $600 \mathrm{~km}$ on the ground, both mean winds and intensities are quite different. The Mawson observing region is either under or enters the auroral oval early in the night and remains there most of the night. The intensity of the emission increases year by year, as expected, with increasing solar and geomagnetic activity. Although there is some point to point variability, hourly mean vertical winds are negative until 19:00 UT and then positive for the second half of the night. The amplitude of the hourly-mean vertical winds at Mawson is generaly less than at Davis.

Mean vertical winds are small and improved statistics are obtained by combining the data sets. There are sufficient similarities between the individual years to justify doing this, however, it should be kept in mind that there are differences
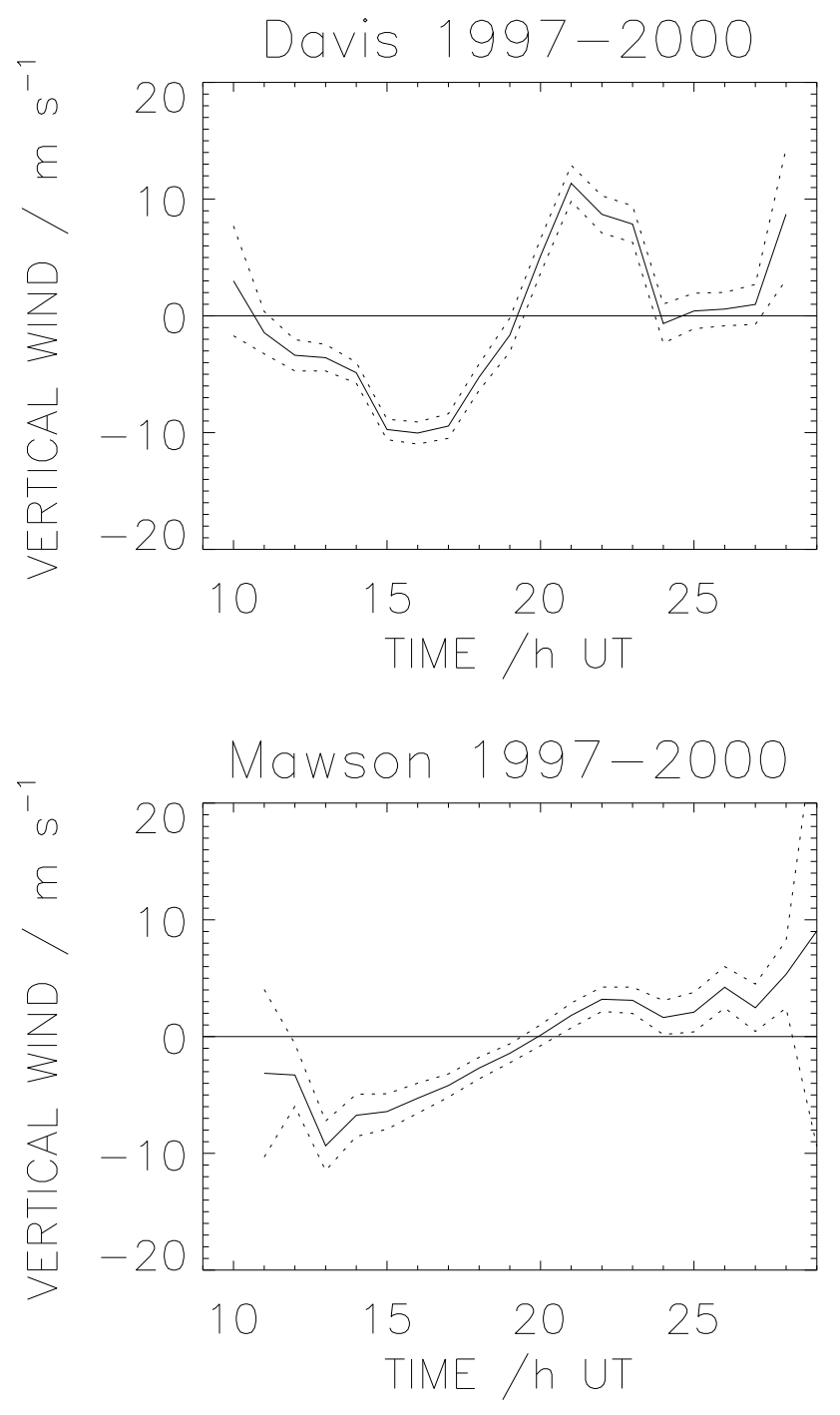

Fig. 3. Hourly mean vertical winds and intensity for the combined four-year data set, 1997-2000, for the two stations, Davis (top) and Mawson (bottom).

from year to year. Figure 3 shows the mean wind for the four combined years, for Davis and Mawson. Mean vertical winds at the two stations have some similar characteristics, generally negative or downward winds in the first half of the night, and positive or upward winds in the second half of the night. Davis mean vertical winds show more structure than those at Mawson, and are larger. Intensities are not plotted, since they indicate general auroral conditions similar to that deduced from Figs. 1 and 2.

Selection procedures may bias the results shown here. Inside the polar cap emission intensity is very weak causing more profiles with poor signal-to-noise values. These are rejected, since routine analysis of such profiles sometimes results in incorrect values and the quantity of data precluded assessment of individual measurements. This would affect Davis data more than Mawson data. Less than $10 \%$ of the profiles were rejected from Davis data, both for high 
backgrounds and poor signal-to-noise values. Effects of excluding profiles with low signal-power to noise-power ratios should not be large, given that the remaining data also indicate weaker intensities of polar cap emissions.

Histograms of all measurements, as shown by Conde and Dyson (1995), give a better indication of the spread of measurements than standard errors in hourly means. Histograms of four years of data for Davis and Mawson are given in Fig. 4. The histograms are drawn from -100 to $+100 \mathrm{~m} \mathrm{~s}^{-1}$ for consistency. The total number of points, the number of points greater than $+100 \mathrm{~m} \mathrm{~s}^{-1}$, and less than $-100 \mathrm{~m} \mathrm{~s}^{-1}$ are given.

The width of the Davis distribution is larger than that for Mawson, as judged by the standard deviation of the Gaussian curves fitted to both histograms. (We find for Davis: $25.13 \pm 0.02 \mathrm{~m} \mathrm{~s}^{-1}$; for Mawson: $19.99 \pm 0.02 \mathrm{~m} \mathrm{~s}^{-1}$, where the quoted error is the uncertainty in the fit). Both Davis and Mawson show a very small offset to negative values, and both Davis and Mawson histograms are largely symmetrical. There are slightly more negative winds near $50 \mathrm{~m} \mathrm{~s}^{-1}$ at Mawson than positive winds of similar magnitude. This could be due to downward winds associated with the poleward edge of the auroral oval. The major difference between the two histograms is that the wings of the Davis profile are considerably larger than the wings of the Mawson profile, indicating more large winds at Davis, both positive and negative. The number of measurements greater than $|100| \mathrm{m} \mathrm{s}^{-1}$ are given in Fig. 4; $0.2 \%$ of Mawson measurements and $1.5 \%$ of Davis measurements. The number of measurements greater than $|50| \mathrm{m} \mathrm{s}^{-1}$ is $5 \%$ at Mawson and $13 \%$ at Davis.

Histograms for individual years, not shown here, also indicate more higher absolute velocities at Davis compared to Mawson in each individual year. Details of the mean and median velocity, and the numbers greater than $|50|$ and $|100| \mathrm{m} \mathrm{s}^{-1}$ are given in Table 2. Individual years are, in general, similar to combined years in Fig. 4. However, the Mawson 1997 distribution is more similar to the Davis distributions than the Mawson distributions in other years. The width of the distribution is wider and there are more higher absolute velocities, but again, not as many as at Davis in 1997. In this year solar activity was low. In 1998 the Davis distribution is more like those typically seen at Mawson, although again, it has broader wings than the Mawson 1998 distribution. Of the four years, the two 1997 distributions are most alike. The Davis 2000 distribution is the broadest of all individual years at both stations.

Annual mean and median vertical winds are negative (Table 2). Standard errors in the mean indicate that the deviation from zero is not significant in all years. This result may reflect that we do not sample a full $24 \mathrm{~h}$, that the length of the observing night varies during the year, and that some partial nights are included in the data; hence, we would not fully sample any diurnal periodicities. Rest wavelength for each night is determined from the average vertical wind. This should hold true for a sufficiently long interval but may introduce an offset for individual nights. Mean and median of the annual data set and the combined data sets indicate that
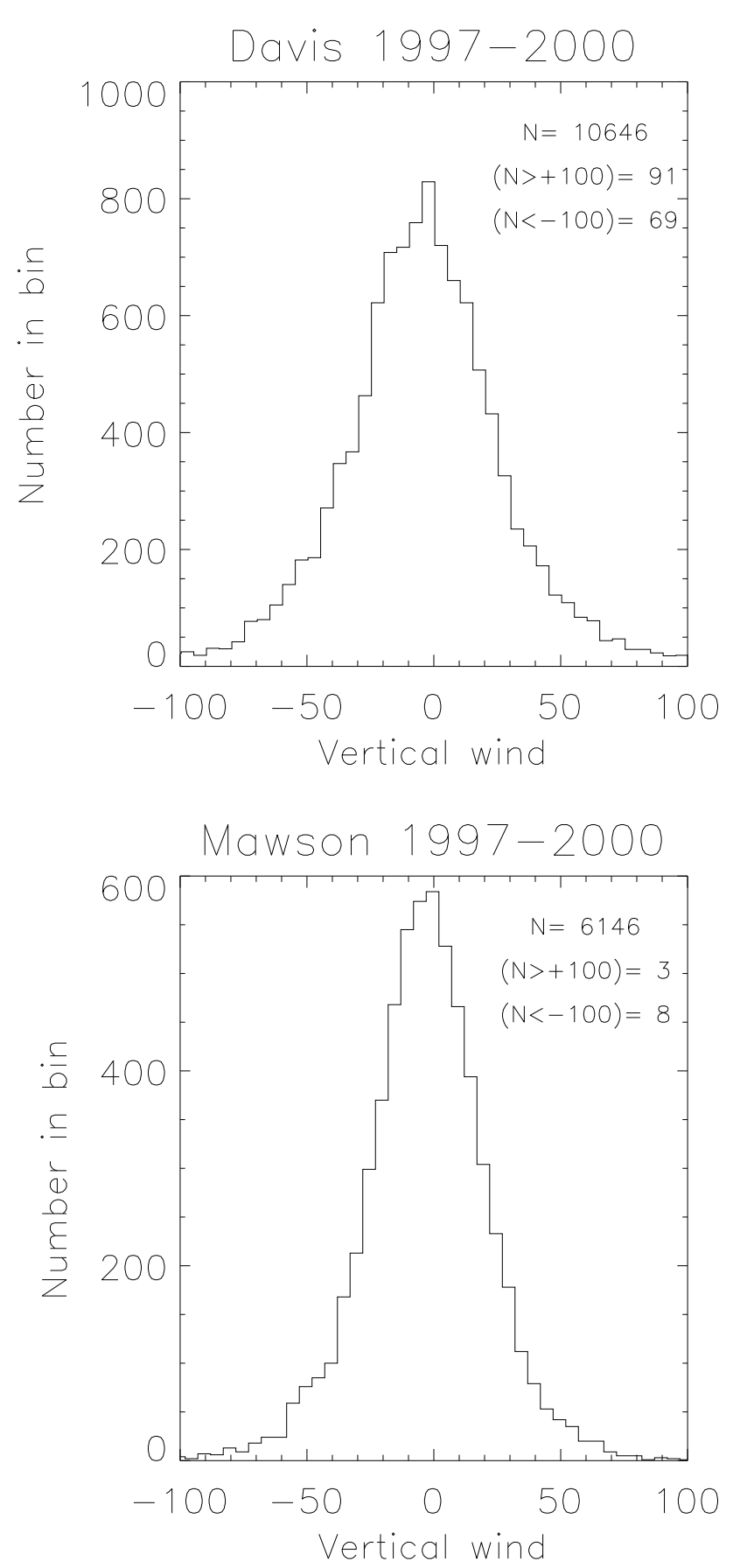

Fig. 4. Histograms of all vertical winds for the four years, 19972000, for the two stations, Davis and Mawson. The total number of points in each analysis, together with the number of points greater than the maximum and less than the minimum shown, are displayed in the top right.

the magnitude of the offset is small, and much smaller than errors in individual measurements, typically $15 \mathrm{~m} \mathrm{~s}^{-1}$, and is probably of no significance other than reflecting the incomplete sampling noted above. An offset would also not affect the shape of the distributions in Figs. 1-4, but would change the location of zero (Aruliah and Rees, 1995). The described wind variations would be unaltered. 
Table 2. Mean, standard error, and median vertical velocities for individual years and the combined data sets from Mawson and Davis. Percentage of measurements $>|50| \mathrm{m} \mathrm{s}^{-1}$ and $>|100| \mathrm{m} \mathrm{s}^{-1}$ are given. The number of profiles can be obtained from Table 1

\begin{tabular}{lrrrrr}
\hline $\begin{array}{l}\text { Station } \\
\text { year }\end{array}$ & $\begin{array}{r}\text { mean } \\
\text { velocity }\end{array}$ & $\begin{array}{r}\text { stnd } \\
\text { error }\end{array}$ & $\begin{array}{r}\text { median } \\
\text { velocity }\end{array}$ & $\begin{array}{r}\% \\
>|50|\end{array}$ & $\begin{array}{r}\% \\
>|100|\end{array}$ \\
\hline $\begin{array}{l}\text { Mawson } \\
1997\end{array}$ & -0.6 & 0.7 & -0.8 & 8 & 0.2 \\
1998 & -1.3 & 0.7 & -1.1 & 3 & 0.2 \\
1999 & -0.4 & 0.6 & -0.7 & 4 & 0.1 \\
2000 & -1.3 & 0.6 & -0.2 & 5 & 0.2 \\
$97-00$ & -0.9 & 0.3 & -0.5 & 5 & 0.2 \\
& & & & & \\
Davis & & & & & \\
1997 & -2.6 & 0.8 & -1.7 & 12 & 0.8 \\
1998 & -0.3 & 0.8 & -0.3 & 7 & 0.1 \\
1999 & -1.5 & 0.4 & -2.1 & 11 & 1.0 \\
2000 & -1.7 & 1.3 & -1.6 & 25 & 5.8 \\
$97-00$ & -1.6 & 0.3 & -1.7 & 13 & 1.5 \\
\hline
\end{tabular}

\section{Variations with magnetic activity}

Planetary $K_{p}$ has been used to investigate variations in the hourly mean vertical wind. The index is readily and promptly available on the web and usually reflects changes in local $K$ indices, which are obtainable for Mawson but not for Davis. Comparisons of $K_{p}$ and $K$ for Mawson show that trends are usually similar, although values of local $K$ tend to be higher than those of $K_{p}$ for the same interval. Changes in magnetic activity will induce changes in the neutral wind due to ion drag. Time taken for such changes varies with ion density but is typically several hours (Kosch et al., 2001). In view of the variability in the coupling time and the time span of $K_{p}$ measurements, $3 \mathrm{~h}$, we have not tried to incorporate a time lag between vertical wind measurements and $K_{p}$ values. Effects would only be significant when $K_{p}$ undergoes step changes of the order of the $K_{p}$ intervals being used. With step sizes of 2 or more, such changes do occur but not frequently.

At Mawson there are remarkably few significant changes in the mean hourly wind at different $K_{p}$ intervals. Mean emission intensity increases with increasing $K_{p}$ but shows no significant structure. At Davis there is more structure in both the hourly mean wind and intensity. Figure 5 shows the Davis data set divided into four $K_{p}$ ranges: 0.0-1.0, 1.3-2.0, 2.3-4.0, and 4.3-9.0. These ranges have been chosen to provide a reasonable number of points in each data set and to illustrate the major features of $K_{p}$ variability. For a $K_{p}$ of 0.0-1.0 Davis is equatorward of the oval in the early evening and vertical winds are slightly negative. Peak auroral activity occurs near 15:00 UT and, as the station moves under the poleward side of the oval, downward vertical winds increase until the station moves under the polar cap, about 18:0019:00 UT. Around 20:00 UT, when the station is under the polar cap, the vertical wind swings dramatically from downward to a maximum upward velocity near 21:00 UT. The vertical wind then slowly decreases, becoming slightly negative prior to dawn.

Increasing $K_{p}$ affects the timing and amplitude of the changes. For a $K_{p}$ of 1.3-2.0 the station enters the auroral oval earlier, 11:00-12:00 UT, and maximum downward velocities are also recorded earlier, 15:00-16:00 UT. Maximum upward velocity is later, 22:00 UT, and substantially higher than that for the lower $K_{p}$ interval. For a $K_{p}$ of 2.3-4.0, representing moderately disturbed conditions, Davis is under the auroral oval by 11:00 UT. Observations at 10:00 UT suggest downward vertical winds, as seen on entering the oval for lower $K_{p}$ intervals. However the small number of points involved does not provide convincing evidence. The maximum downward velocity at 16:00 UT, when Davis enters the polar cap, is substantially larger, $-18 \mathrm{~m} \mathrm{~s}^{-1}$, than that for lower $K_{p}, \sim-10 \mathrm{~m} \mathrm{~s}^{-1}$.

For magnetically active conditions, $4.3<K_{p}<9.0$, there are not as many data points as for lower $K_{p}$ intervals. Trends noted above continue. The change from negative to positive winds occurs at 18:00 UT, a change of approximately $2.5 \mathrm{~h}$ from the quietest conditions. Maximum and minimum velocities are larger, and these velocities are sustained for longer than at lower activity. There is a suggestion of a twelve hour periodicity, from 12:00 to 24:00 UT, however, the number of data points outside this interval is not sufficient to determine if this is an oscillation sustained over $24 \mathrm{~h}$, or a variation due to other effects. Hourly intensity averages are more variable in this $K_{p}$ interval, possibly due to the smaller number of points or/and due to substorms expanding overhead from the oval equatorward of Davis. The mean intensity of $\sim 5$ units from 15:00 to 02:00 UT is representative of moderate aurora and indicates that at these times substorms bring the oval over Davis relatively frequently.

The appearance of Fig. 5 is similar to Fig. 1 (Davis mean vertical winds 1997-2000). In large part this is due to the generally monotonic increase in mean geomagnetic activity over this time interval, so that separating by $K_{p}$ is similar to separating by year.

Mawson, in comparison to Davis, has a remarkably constant vertical wind pattern. Figure 6 shows three $K_{p}$ ranges, 0.0-2.0, 2.3-4.0, and 4.3-9.0. Using smaller increments in $K_{p}$ did not isolate any other features. Compared to the Davis mean winds, those at Mawson are remarkably consistent both from year to year and with variations in $K_{p}$. There is a suggestion of slightly higher winds at higher $K_{p}$, however, the number of data points at higher $K_{p}$ is not sufficient for this to be significant. Mean intensity increases with increasing $K_{p}$ at Mawson. The station is under the auroral oval for most of the night. Auroral videos suggest that the Mawson observing region usually passes under the equatorward edge of the auroral oval in the evening. Intensity plots, for both Davis and Mawson, reflect changes in the emission intensity other than auroral changes. In the evening (and morning) twilight the emission intensity decreases (increases) due to photochemical effects. Entry into the auroral oval in the evening at Maw- 

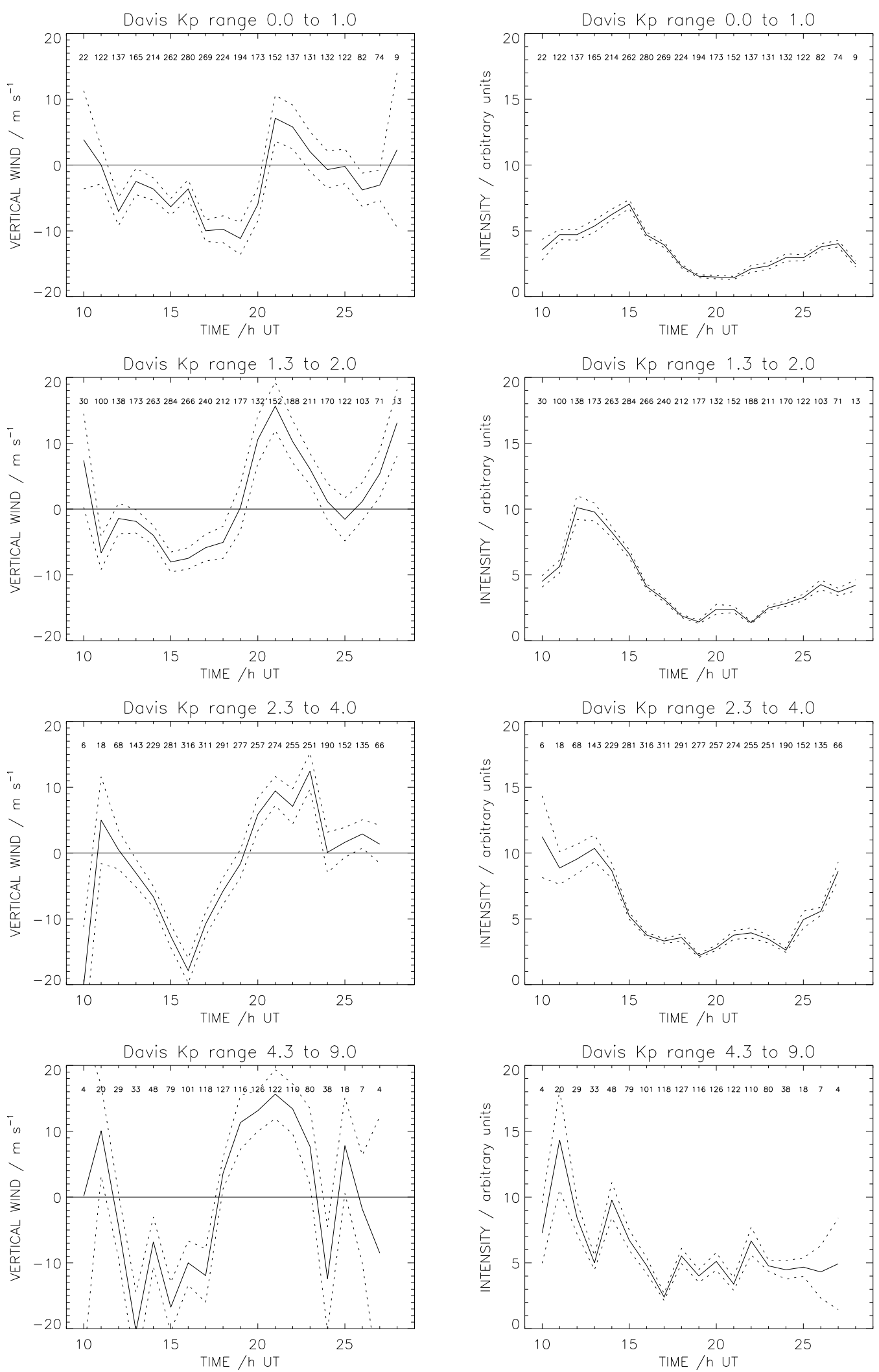

Fig. 5. Davis hourly mean vertical winds (left) and intensity (right) in four $K_{p}$ ranges, 0.0 to $1.0,1.3$ to $2.0,2.3$ to 4.0 and 4.3 to 9.0 . The number of points in hourly means are indicated at the top of the plots. Standard errors are indicated by dashed lines. 

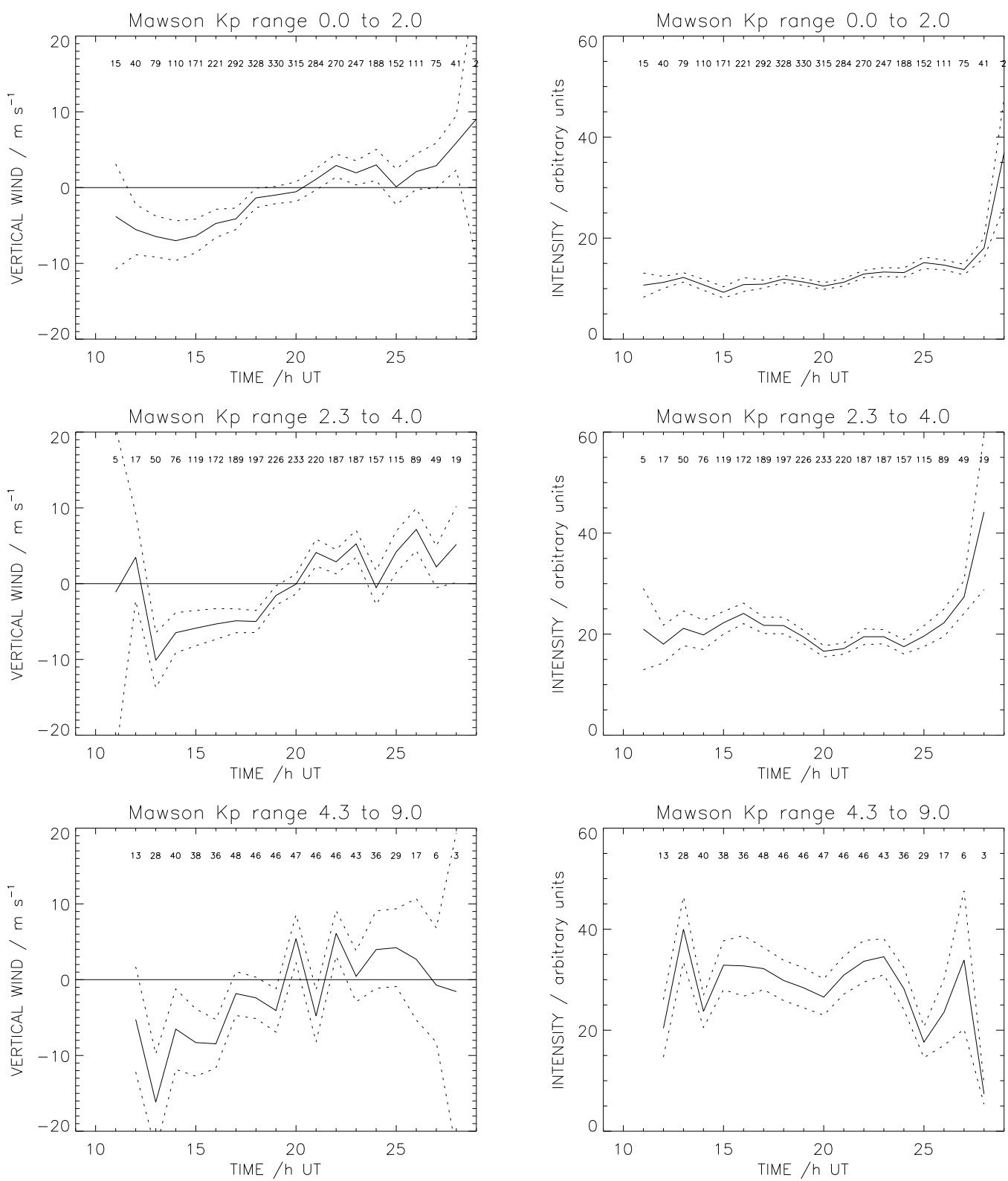

Fig. 6. Mawson hourly mean vertical winds (left) and intensity (right) in three $K_{p}$ ranges, 0.0 to $2.0,2.3$ to 4.0 , and 4.3 to 9.0 . The number of points in hourly means are indicated at the top of the plots. Standard errors are indicated by dashed lines.

son, seen in auroral videos, is masked by the early evening decrease in emission intensity. The downward spike in vertical winds at 13:00 UT, for $K_{p}>2.3$, is probably an indicator of entry of the observing region into the auroral oval.

Conde and Dyson (1995) found an increase in the width of the histogram of Mawson vertical winds with increasing $K_{p}$, however, although there was a tendency towards this in our data set, it was not significant. The number of large vertical wind measurements did not show a definitive trend either. The tendency to asymmetry with more downward vertical winds near $50 \mathrm{~m} \mathrm{~s}^{-1}$ is less apparent for disturbed days, both in our data set and that of Conde and Dyson (1995). With more measurements at high $K_{p}$ a trend may be determined.

Histograms of Davis vertical wind velocities for different increments in $K_{p}$ (not presented here, but summarised in Table 3) show more defined trends. The width of the histogram increases with increasing $K_{p}$, and the number of large vertical winds, both those greater than $|50| \mathrm{m} \mathrm{s}^{-1}$ and $|100| \mathrm{m} \mathrm{s}^{-1}$, increases with increasing $K_{p}$. Table 3 gives the percentage of these occurrences for the $K_{p}$ intervals in Fig. 5. There are approximately twice as many high velocity measurements for $4.3<K_{p}<9.0$ as there are for $0.0<K_{p}<1.0$.

The symmetry of the Davis histograms also varies with $K_{p}$, however, there is no consistent trend. For $1.3<K_{p}<$ 2.0 the histogram is approximately symmetrical. For $0.0<$ $K_{p}<1.0$ and $2.3<K_{p}<4.0$ there are more downward winds than upward winds over a range of velocities. For the most active range, $4.3<K_{p}<9.0$, there are more upward 
Table 3. Davis vertical winds selected by $K_{p}$

\begin{tabular}{lccc}
\hline$K_{p}$ interval & total $N$ & $N>|50| \mathrm{m} \mathrm{s}^{-1}$ & $N>|100| \mathrm{m} \mathrm{s}^{-1}$ \\
\hline $0.0-1.0$ & 2901 & $9 \%$ & $0.8 \%$ \\
$1.3-2.0$ & 3045 & $12 \%$ & $1.4 \%$ \\
$2.3-4.0$ & 3520 & $14 \%$ & $1.7 \%$ \\
$4.3-9.0$ & 1180 & $17 \%$ & $2.8 \%$ \\
\hline
\end{tabular}

winds than downward winds, particularly in the range 20 $50 \mathrm{~m} \mathrm{~s}^{-1}$.

\section{Discussion}

A clear dependence on $K_{p}$ can be seen in the Davis data, and yet Mawson data do not show such a marked dependence. As noted by other authors (McCormac et al., 1987; Killeen et al., 1988; Aruliah and Rees, 1995), location of the auroral oval is also dependent on $K_{p}$. Hourly mean intensity plots in Fig. 6 imply that for ranges of $K_{p}$ in our data, Mawson is within the auroral oval for most of the night. The location of Davis, with respect to the auroral oval, varies with $K_{p}$ and variations are also seen in the mean vertical wind. From this we conclude that it is the auroral oval, features associated with the passage of the auroral oval, or the auroral-oval polar-cap boundary, rather than $K_{p}$ per se, which is driving the large variations in vertical wind seen at Davis. Figure 7 is a schematic based on the auroral-oval model of Holzworth and Meng (1975), showing mean hourly winds from Davis and Mawson in geomagnetic polar coordinates (magnetic local time, MLT, and Invariant latitude - at Davis, MLT UT $+2 \mathrm{~h}$, and at Mawson, MLT $\sim \mathrm{UT}+1.5 \mathrm{~h}$ ). Their model was based on the (now obsolete) $Q$-index. We use the relationships derived by Starkov (1994) to convert from $Q$ to $K_{p}$, and show the schematic ovals for $Q=1\left(K_{p} \sim 1\right)$ and $Q=5\left(K_{p} \sim 4\right)$ to represent the $K_{p}<2$ and $K_{p}>3$ cases. This model oval should be used for general orientation only - the relative intensity data form a more suitable guide for estimating the instantaneous oval position relative to the observing stations. For the quiet auroral oval, winds from intervals with $K_{p}<2$ were averaged and, for the active auroral oval, winds from intervals when $K_{p}>3$ were averaged. The average vertical winds shown in Fig. 7 do not represent the velocity distributions of Fig. 4. A significant number of measurements $>|50| \mathrm{m} \mathrm{s}^{-1}$ are included in some intervals and instances of winds to $200 \mathrm{~m} \mathrm{~s}^{-1}$ have been reported (Innis et al., 1999). Tables 2 and 3 indicate that there are more high velocities at Davis than Mawson and at Davis there are more high velocities at high $K_{p}$ than at low $K_{p}$.

Figure 7 provides a spatial presentation of data presented in Figs. 5 and 6. At low geomagnetic activity Davis passes under the oval in the evening. Hourly mean vertical winds are small in magnitude at these times, similar to those seen later in the night at Mawson. During high geomagnetic activity Davis is under the polar cap in the evening, and mean

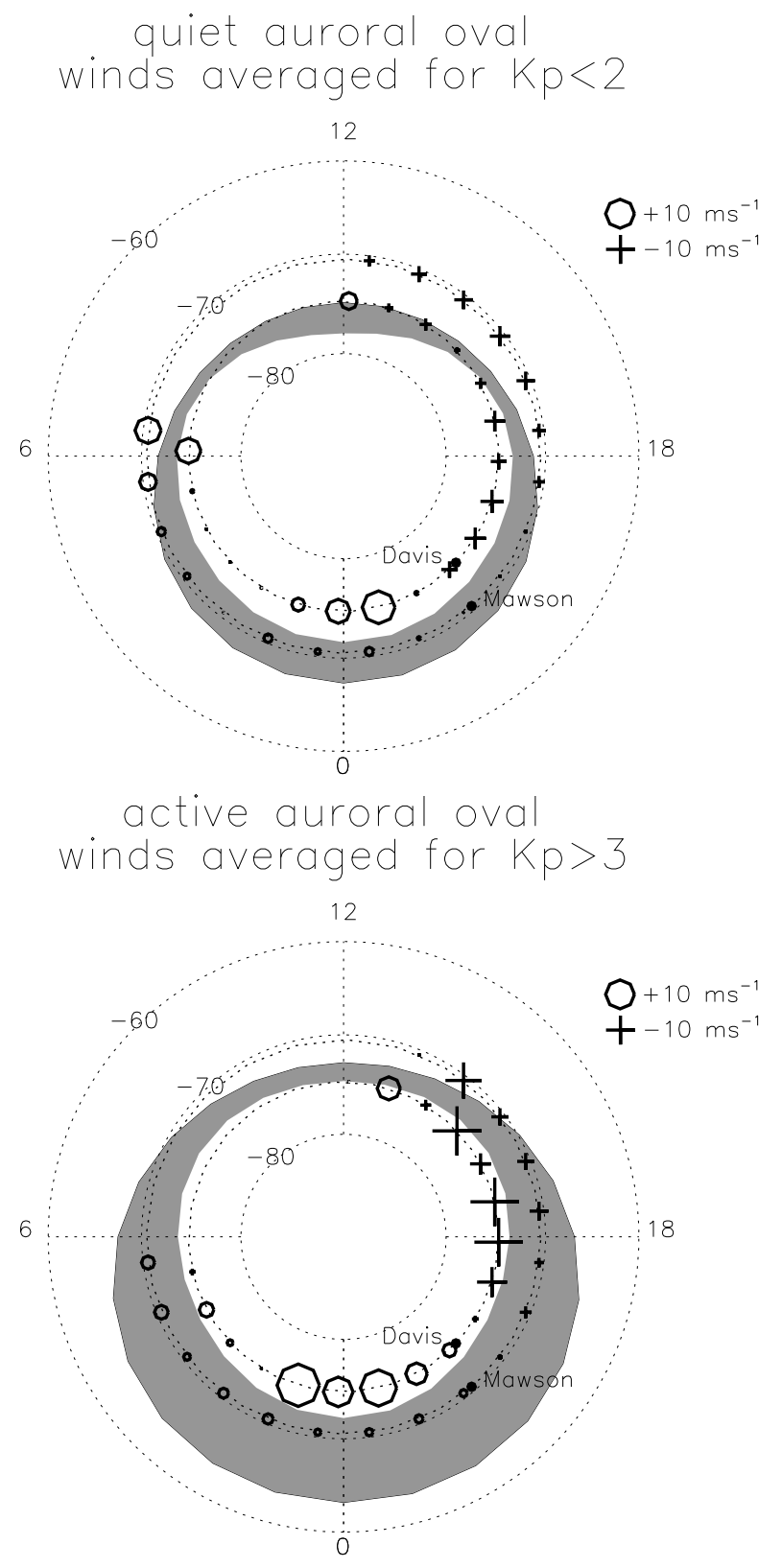

Fig. 7. Hourly mean vertical winds from Davis and Mawson with respect to the auroral oval at geomagnetically quiet (top) and active (bottom) conditions, based on a model by Holzworth and Meng (1975). For the quiet auroral oval, winds from intervals when $K_{p}<2$ were averaged and for the active auroral oval, winds from intervals when $K_{p}>3$ were averaged. A wind scale is indicated on the right; local magnetic time on the perimeter of the map; and local midnight by filled circles labelled with station names.

vertical winds are significantly larger. There are large upward winds at magnetic midnight inside the polar cap. These winds are enhanced both in magnitude and spatial extent at times of higher geomagnetic activity. Local midnight is approximately the time of transition from negative to positive vertical winds. Figure 5 suggests this transition varies with $K_{p}$ at Davis by up to $2.5 \mathrm{~h}$ and so its occurrence at local mid- 
night may be coincidental. Although precise details of this auroral oval model may not be completely accurate, Fig. 7 shows how the auroral oval explains why the two stations, geographically in close proximity, experience quite different mean thermospheric vertical winds.

Our mean vertical winds at Mawson, Fig. 3, show similar magnitudes to those reported by Conde and Dyson (1995). A discussion by Conde and Dyson (1995) indicated that these magnitudes were less than those seen by others. They are also less than those seen at Davis. This may be due to Mawson's extended interval under the auroral oval, with only occasional movement into the polar cap, as compared to the regular presence of the polar cap over Davis. As noted recently (Conde and Smith, 1998; Greet et al., 1999), auroral substorms can produce a doldrums in the neutral wind field. Frequent quiet or stagnant wind fields, associated with the auroral oval, may combine to reduce Mawson's mean vertical wind.

Some features of the hourly mean vertical wind would appear to be directly linked to the auroral oval. Crickmore et al. (1991) noted downward winds on the equatorward side of the auroral oval. We also see such winds at Davis at 12:00 UT $\left(\sim 14\right.$ MLT) for $0.0<K_{p}<1.0$, at 11:00 UT for $1.3<K_{p}<2.0$, and possibly at 10:00 UT for $2.3<K_{p}<4.0$. As mentioned previously, good statistics to support the last claim do not exist. We see the feature at Mawson, at 13:00 UT for 2.3 $<K_{p}<4.0$ and at 13:00 UT for $4.3<K_{p}<9.0$. Conde and Dyson (1995) did not note this feature in the hourly averaged vertical winds, but this may have been due to filtering the data with a "flat-topped Gaussian" function with a full width of $2 \mathrm{~h}$. Crickmore et al. (1991) were able to enhance the feature, for a small data set, by shifting each night's observations to align the auroral oval crossing in time. Sufficiently small $K_{p}$ increments, with adequate data and no smoothing, permit the identification of this feature in our data. The downward wind on the equatorward side of the oval is not seen at Davis for the most active $K_{p}$, simply because Davis is under the auroral oval or possibly the polar cap, by the time observations commence. At Mawson it does not stand out for the quietest $K_{p}$, however, it may be present, but not sufficiently different from other trends to be visually identifiable.

Vertical wind events with velocities up to $200 \mathrm{~m} \mathrm{~s}^{-1}$ have been seen at the auroral oval/polar cap boundary over Mawson and Davis (Innis et al., 1996, 1997, 1999). Previous analyses of these vertical wind events have been on an individual basis and every data point was scrutinized. Some of these velocity measurements would not have been included in this analysis due to more rigid rejection criteria for low signal-to-noise profiles, necessary for handling the large data set involved in this study. A lower bound on emission intensity can be used as a selection criteria to reject measurements from the polar cap.

For data that pass the signal-to-noise criteria, we use the measured relative intensity to separate into high-intensity (characteristic of the auroral oval) and low-intensity (characteristic of the polar cap) categories. An arbitrary value of
Table 4. Vertical winds selected by intensity and then $K_{p}$, at both Mawson and Davis. The percentage of measurements $>|50| \mathrm{m} \mathrm{s}^{-1}$ and $>|100| \mathrm{m} \mathrm{s}^{-1}$ is also given

\begin{tabular}{|c|c|c|c|c|}
\hline & $K_{p}$ & $N$ & $N>|50| \mathrm{ms}^{-1}$ & $N>|100| \mathrm{ms}^{-1}$ \\
\hline \multicolumn{5}{|c|}{ Mawson } \\
\hline$I>2$ & all $K_{p}$ & 5553 & $4 \%$ & $0.1 \%$ \\
\hline$I>2$ & $K_{p}<2$ & 2826 & $4 \%$ & $0.1 \%$ \\
\hline$I>2$ & $K_{p}>2$ & 2727 & $4 \%$ & $0.1 \%$ \\
\hline $\mathrm{I}<2$ & all $K_{p}$ & 593 & $15 \%$ & $1 \%$ \\
\hline$I<2$ & $K_{p}<2$ & 445 & $14 \%$ & $0.7 \%$ \\
\hline$I<2$ & $K_{p}>2$ & 148 & $18 \%$ & $1 \%$ \\
\hline \multicolumn{5}{|l|}{ Davis } \\
\hline$I>2$ & all $K_{p}$ & 5960 & $5 \%$ & $0.2 \%$ \\
\hline$I>2$ & $K_{p}<2$ & 3245 & $3 \%$ & $0 \%$ \\
\hline$I>2$ & $K_{p}>2$ & 2715 & $7 \%$ & $0.4 \%$ \\
\hline$I<2$ & all $K_{p}$ & 4686 & $22 \%$ & $3 \%$ \\
\hline$I<2$ & $K_{p}<2$ & 2701 & $20 \%$ & $2 \%$ \\
\hline$I<2$ & $K_{p}>2$ & 1985 & $25 \%$ & $4 \%$ \\
\hline
\end{tabular}

2 was used as a cutoff for low intensity measurements. Using lower values as a cutoff would provide more certainty that measurements were from the polar cap, however, not enough data points were then accepted to make useful conclusions. Most measurements for which the emission intensity was less than 2 would be from the polar cap, although they may still include some measurements with auroral contributions. Most measurements with an emission intensity greater than 2 would be from the auroral oval and equatorward of the oval. There was no simple selection criteria to separate measurements from the oval from those equatorward of the oval. Particularly in the early evening, aurora are diffuse and their intensities not significantly different from airglow emissions equatorward of the oval. Selecting only high intensity measurements would select auroral substorms, primarily occurring near magnetic midnight, and would not be representative of the oval as a whole. Mawson has few measurements with low intensity. The observing region does pass into the polar cap but not for extended periods or as regularly as at Davis, where the distribution of low intensity measurements was not spread evenly through the night. There were more measurements with an intensity of less than 2 after the first $6 \mathrm{~h}$ of observations.

Low intensity measurements have higher absolute hourly mean velocities. Histograms of velocities show narrow distributions for high intensity measurements and broad distributions for low intensity measurements. Table 4 shows the number of measurements at low and high intensity, further divided into low and high $K_{p}$, and the percentage of outliers for each case. Both low intensity and high $K_{p}$ are associated with larger vertical winds. Figure 8 shows mean hourly vertical winds and histograms for high intensity, low $K_{p}$ intervals for both Mawson and Davis. Low intensity, high $K_{p}$ 

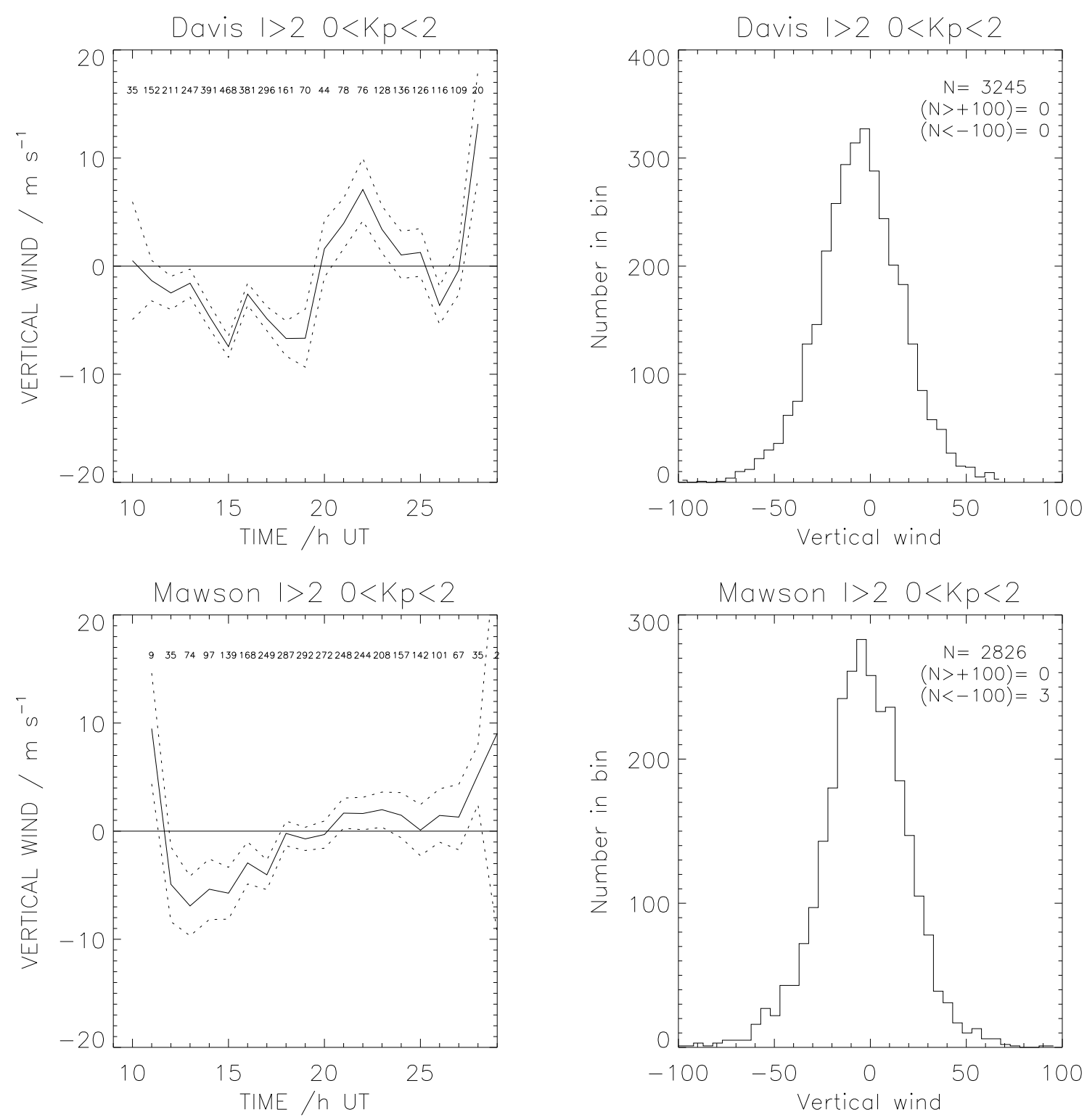

Fig. 8. Hourly mean vertical winds and histograms for high intensity, low $K_{p}$, measurements from Davis and Mawson. As in Fig. 4 the total number and outliers are given. The majority of these measurements would be from the auroral oval.

hourly winds and histograms for Davis are given in Fig. 9. Mawson values for the latter are not shown, since insufficient measurements meet the selection criteria. Character of the Mawson values is similar to those shown from Davis, as can be verified from Table 4 .

Mawson and Davis, high intensity, low $K_{p}$, hourly mean vertical winds and histograms are much more similar, in terms of the fraction of observations exceeding $|50| \mathrm{m} \mathrm{s}^{-1}$, than compared to the low intensity, high $K_{p}$, hourly mean vertical winds and histograms. Separating the intensityselected data by $K_{p}$ has a relatively minor effect on the percentage occurrence of large winds, compared with the changes seen when separating by low $(I \leq 2)$ and high $(I>2)$ intensity. This suggests that it is the proximity to the auroral oval, rather than $K_{p}$, which has a greater effect on the measured vertical wind. Selection by intensity divides measurements primarily into those from under the auroral oval and those from the polar cap. Although this is a fairly crude technique, it supports the hypothesis that vertical winds inside the polar cap are more variable and often of higher speeds than vertical winds within the auroral oval.

Davis and Mawson hourly mean plots in Fig. 8 are more similar than the two Davis data sets in Figs. 8 and 9. Effects due to, for example, entry into the auroral oval, are still present in the quiet data in Fig. 8. Simple intensity selection may not always adequately select auroral oval or polar cap measurements, particularly at Davis. This is also suggested by the Davis histogram of vertical winds, which is slightly more asymmetrical than the Mawson histogram in Fig. 8. Ignoring end effects produced by few data points and possi- 

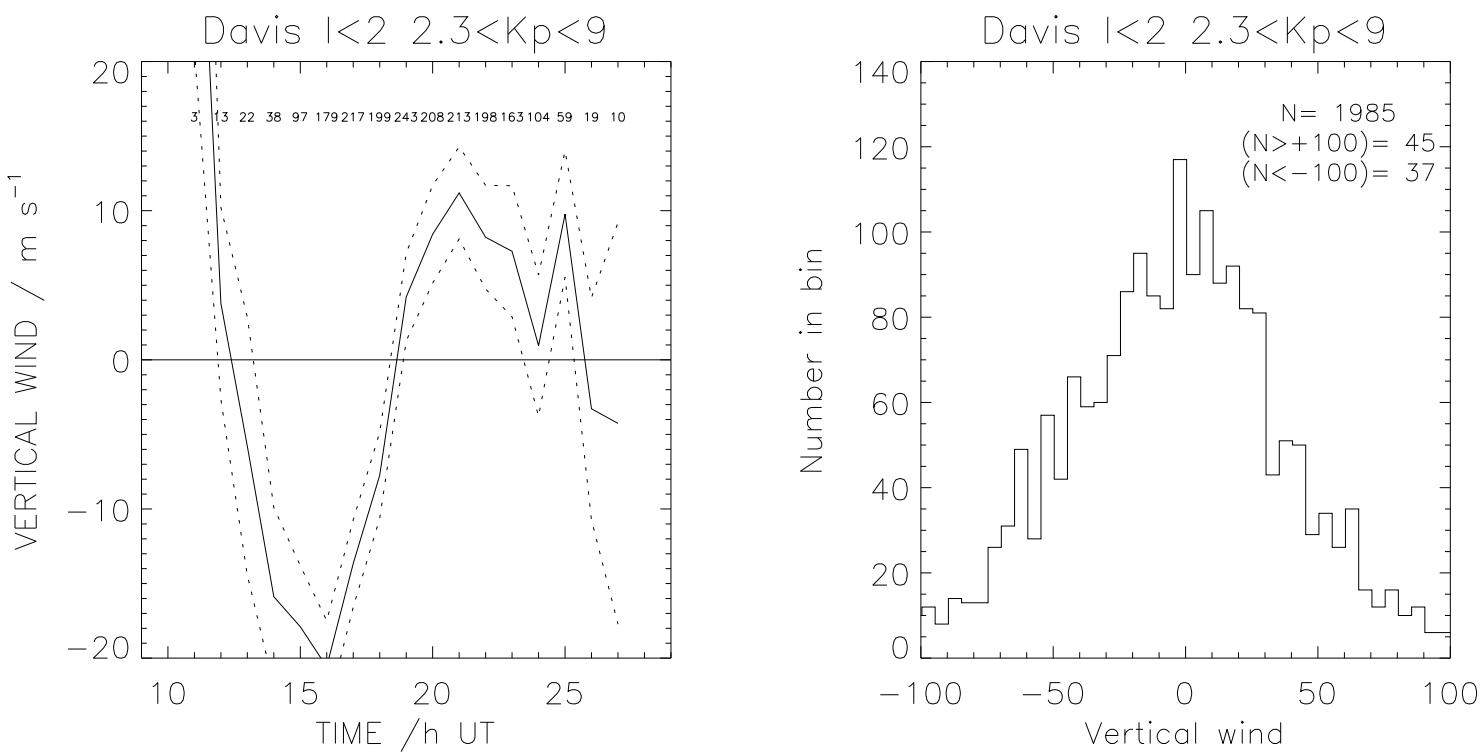

Fig. 9. As in Fig. 8 except for low intensity, high $K_{p}$. Only Davis values are given, since insufficient data were available from Mawson. The majority of these measurements would be from the polar cap.

ble contamination of Davis auroral oval data, thermospheric vertical winds within the auroral oval are slightly negative in the first half of the night and slightly positive in the second half of the night. Noting that the evening negative excursions may still be affected by the entry into the auroral oval, the magnitude of the mean auroral oval thermospheric vertical winds may be as little as $2 \mathrm{~m} \mathrm{~s}^{-1}$ during low $K_{p}$ intervals. This is the order of magnitude suggested by Smith (1998) for the diurnal expansion and contraction of the thermosphere. The transition from negative to positive vertical winds occurs slightly after 20:00 UT at Mawson and slightly before 20:00 UT at Davis, in both cases approximately $2 \mathrm{~h}$ prior to magnetic midnight. Local midnight is at 18:48 UT at Davis and 19:48 UT at Mawson, approximately $1 \mathrm{~h}$ before the transition. Figure 6 suggests that within the auroral oval the transition is not greatly effected by $K_{p}$ and also not well defined. At Davis the transition is more rapid, well defined, and varies with $K_{p}$. The transition from negative to positive vertical winds may be determined by local midnight, however, at this time, the thermosphere is complex, and isolating individual features and their drivers is difficult.

Thermospheric vertical winds inside the polar cap are significantly more complicated. They follow the same basic pattern of being negative in the evening and positive prior to dawn. Amplitudes are more dependent on $K_{p}$, with absolute amplitudes at maximum mean velocities of $10-15 \mathrm{~m} \mathrm{~s}^{-1}$ for $K_{p}<2$ and $15-20 \mathrm{~m} \mathrm{~s}^{-1}$ for $K_{p}>2$. The timing and rate of transition from negative to positive velocities is earlier, faster, and at larger amplitudes, for increasing $K_{p}$.

We have shown that mean vertical winds are linked to the auroral oval, however, consideration should also be given to thermospheric circulation. In the polar thermosphere antisunward pressure-gradient winds are modified by ion-drag, which couples the neutral atmosphere to magnetospheric convection. Depending on the number of ions present, typically one or two polar circulation cells are formed; evening and morning circulation cells with an anti-sunward crosspolar jet between them (Heppner and Maynard, 1987; McCormac et al., 1987; Smith et al., 1998). As with the auroral oval, the location of the centres of the circulation cells and the size of the cells varies with $K_{p}$. The number of cells, their size, and shape are controlled by the interplanetary magnetic field, the IMF. A detailed study of the vertical wind and the IMF is beyond the scope of this paper and will be the subject of future study and modelling. However, some simple observations are appropriate when interpreting Davis vertical wind data.

Davis, at $74.6^{\circ} \mathrm{S}$ magnetic, would, for most $K_{p}$, pass through or near the centre of the evening circulation cell near 16-17 LMT (local magnetic time), approximately 18:0019:00 UT, and through or near the centre of the dawn circulation cell, when it exists, about 04-05 LMT or 06:0007:00 UT. Large downward winds at 15:00-19:00 UT in Fig. 7 may be associated with the centre of the evening circulation cell. These winds are more marked during higher $K_{p}$, when the evening circulation cell is stronger. The dawn cell is generally significantly weaker than the dusk cell and is not always seen in thermospheric neutral winds. When passing through the centre of the dawn cell, both stations are in bright twilight at mid-winter and so single-etalon FPS observations are not possible. In the evening the transition from negative to positive vertical winds occurs between 17:00 and 20:00 UT depending on location and $K_{p}$. The rate and amplitude of the transition from negative to positive vertical winds, could be linked to the strength of the circulation cell or width of the cross-polar jet.

Magnetic midnight occurs near 22:00 UT, just after the peak in positive vertical winds. The cross-polar jet generally 
maximizes about two hours after magnetic midnight. In the two hours after magnetic midnight, the thermospheric vertical wind decreases to zero, at a rate dependent on $K_{p}$, again possibly linked to the strength of the polar circulation cells or width of the cross-polar jet. To better study such linkages, careful selection of the intervals of stable IMF and a comparison with modelled magnetospheric induced ion-drag circulation is required.

\section{Conclusions}

Thermospheric mean vertical winds from observations of the $\lambda 630 \mathrm{~nm}$ emission over a four-year interval, 1997-2000, and from two southern high-latitude stations have been presented. Mawson is commonly under the auroral oval for much of any given observing night, while Davis passes from under the auroral oval into the polar cap on most nights. Although only $\sim 600 \mathrm{~km}$ separates the stations on the ground, mean thermospheric vertical winds are quite different at the two stations.

At both stations mean vertical winds are mostly negative in the first half of the night and mostly positive in the second half of the night, divided approximately, and possibly coincidentally, by local midnight. Mawson mean hourly vertical winds vary between $-10 \mathrm{~m} \mathrm{~s}^{-1}$ and $+4 \mathrm{~m} \mathrm{~s}^{-1}$ and show little dependence on $K_{p}$. Davis mean hourly vertical winds vary between $-10 \mathrm{~m} \mathrm{~s}^{-1}$ and $+10 \mathrm{~m} \mathrm{~s}^{-1}$, show significant variations with $K_{p}$, and are generally more structured than Mawson mean hourly vertical winds.

Selecting the data by emission intensity shows that it is the location of the observing station relative to the auroral oval, and polar cap, that is the main influence on the mean vertical wind observed from the site. Three features directly linked to the auroral oval can be identified: low amplitude mean vertical winds within the auroral oval, downward winds associated with passage of the observing region through the equatorward boundary of the oval, and larger winds poleward of the oval, specifically downward winds in the early evening and an upward wind near magnetic midnight.

High intensity and low $K_{p}$ winds from Davis are more similar to high intensity and low $K_{p}$ winds from Mawson than the low intensity high $K_{p}$ winds from Davis. Thermospheric vertical winds from the auroral oval, those with high intensity, are generally significantly less than those from the polar cap region. Histograms of the distribution of vertical winds in the polar cap have greatly extended wings compared to the distribution of vertical winds from the auroral oval.

Further studies of the mean vertical wind and polar thermospheric circulation may show associations between the structure in Davis mean hourly winds and the strength of the polar thermospheric circulation cells and/or the cross-polar jet.

Acknowledgement. This work was supported by the Australian Antarctic Division, La Trobe University, the Australian Antarctic Science Advisory Committee, and the Australian Research Council. Australian National Antarctic Research Expedition personnel, particularly those at Davis and Mawson during the 1997-2000 interval, co-operated to ensure this research was possible. We particularly thank the expeditioners responsible for operation of the FabryPerot Spectrometers whose dedication ensured data were collected during the study interval including: Mike Manion, Chris Boucher, John French, Martin Harvey, Nick Mortimer, Bryndon Booth, Darron Lehman, and Kym Newberry. John Innis acknowledges the hospitality of University of Alaska, Fairbanks, during part of the time this paper was in preparation. We thank the referees for helpful comments.

Topical Editor D. Murtagh thanks M. Kosch and another referee for their help in evaluating this paper.

\section{References}

Aruliah A. L. and Rees, D.: The trouble with thermospheric vertical winds: geomagnetic, seasonal and solar cycle dependence at high latitudes, J. Atmos. Terr. Phys., 57, 597-609, 1995.

Conde, M. and Dyson, P. L.: Thermospheric vertical winds above Mawson, Antarctica, J. Atmos. Terr. Phys., 57, 589-597, 1995.

Conde, M. and Smith, R. W.: Spatial structure in the thermospheric horizontal wind above Poker Flat, Alaksa, during solar minimum, J. Geophys. Res., 103, 9449-9471, 1998.

Crickmore, R. I., Dudney, J. R., and Rodger, A. S.: Vertical thermospheric winds at the equatorward edge of the auroral oval, J. Atmos. Terr. Phys., 53, 485-492, 1991.

Greet, P. A., Conde, M. G., Dyson, P. L., Innis, J. L., Breed, A. M., and Murphy, D. J.: Thermospheric wind field over Mawson and Davis Antarctica; simultaneous observations by two Fabry-Perot spectrometers of $\lambda 630 \mathrm{~nm}$ emission, J. Atmos. Sol. Terr. Phys., 61, 1025-1045, 1999.

Heppner, J. P. and Maynard, N. C.: Empirical high-latitude electric field models, J. Geophys. Res., 92, 4467-4489, 1987.

Holzworth, R. H. and Meng, C.-I.: Mathematical representation of the auroral oval, Geophys. Res. Lett., 2, 377-380, 1975.

Innis, J. L., Greet, P. A., and Dyson, P. L.: Fabry-Perot spectrometer observations of the auroral oval/polar cap boundary above Mawson, Antarctica, J. Atmos. Terr. Phys., 58, 1973-1988, 1996.

Innis, J. L., Dyson, P. L., and Greet, P. A.: Further observations of the thermospheric vertical wind at the auroral oval/polar cap boundary. J. Atmos. Terr. Phys., 59, 2009-2022, 1997.

Innis, J. L., Greet, P. A., Murphy, D. J., Conde, M. G., and Dyson, P. L.: A large vertical wind in the thermosphere at the auroral oval/polar cap boundary seen simultaneously from Mawson and Davis, Antarctica, J. Atmos. Sol. Terr. Phys., 61, 1047-1058, 1999.

Innis, J. L., Greet, P. A., and Dyson, P. L.: Evidence for thermospheric gravity waves in the southern polar cap from groundbased vertical velocity and photometric observations, Ann. Geophysicae, 19, 533-543, 2001.

Jacka, F., Bower, A. R. D., Creighton, D. F., and Wilksch, P. A.: A large-aperture high-resolution Fabry-Perot spectrometer for airglow studies, J. Phys. E: Sci. Instrum., 13, 562-568, 1980.

Jacka, F.: Application of Fabry-Perot spectrometers of upper atmosphere temperatures and winds, in: Middle Atmosphere Program for MAP, (Ed) Vincent, R., ch. 13, 19-40, 1985.

Johnson, F. S., Hanson, W. B., Hodges, R. R., and Coley, W. T. R.: Gravity waves near $300 \mathrm{~km}$ over the polar caps, J. Geophys. Res., 100, 23 993-24 002, 1995.

Killeen, T. L., Craven, J. D., Frank, L. A., Ponthieu, J.-J., Spencer, N. W., Heelis, R. A., Brace, L. H., Roble, R. G., Hays, P. B., and 
Carignan, G. R.: On the relationship between dynamics of the polar thermosphere and morphology of the aurora: Global-scale observations from Dynamics Explorers 1 and 2. J. Geophys. Res., 93, 2675-2692, 1988.

Kosch, M. J., Cierpka, K., Rietveld, M. T., Hagfors, T., and Schlegel, K.: High-latitude ground-based observations of the thermospheric ion-drag time constant, Geophys. Res. Lett., 28, 1395-1398, 2001.

McCormac, F. G., Killeen, T. L., Thayer, J. P., Hernandez, G., Tschan, C. R., and Ponthieu, J.-J.: Circulation of the polar thermosphere during geomagnetically quiet and active times as observed by Dynamics Explorer 2, J. Geophys. Res., 92, 10133 $10139,1987$.

Oyama, S., Nozawa, S., Buchert, S. C., Ishii, M., Watari, S., Sagawa, E., Kofman, W., Lilensten, J., and Fujii, R.: Effects of atmospheric oscillations on the field-aligned ion motions in the polar F-region, Ann. Geophysicae, 18, 1154-1163, 2000.

Price, G. D., Smith, R. W., and Hernandez, G.: Simultaneous mea- surements of large vertical winds in the upper and lower thermosphere, J. Atmos. Terr. Phys., 57, 631-643, 1995.

Smith, R. W.: Vertical winds: a tutorial, J. Atmos. Sol. Terr. Phys., 60, 1425-1434, 1998.

Smith, P. R., Dyson, P. L., Monselesan, D. P., and Morris, R. J.: Ionospheric convection at Casey, a southern polar cap station, J. Geophys. Res., 103, 2209-2218, 1998.

Sojka, J. J., Schunk, R. W., David, M., Innis, J. L., Greet, P. A., and Dyson, P. L.: A theoretical model study of F-region response to high latitude neutral wind upwelling events, J. Atmos. Sol. Terr. Phys., 63, 1571-1584, 2001.

Spencer, N. W., Wharton, L. E., Carnigan, G. R., and Maurer, J. C.: Thermospheric zonal winds, vertical motions and temperature as measured from dynamics explorer, Geophys. Res. Lett., 9, 953956, 1982.

Starkov, G. V.: Statistical dependencies between the magnetic activity indices, Geomag. Aeron., 34, 101-103, 1994. 